\title{
Lumbar Puncture Headache
}

National Cancer Institute

\section{Source}

National Cancer Institute. Lumbar Puncture Headache. NCI Thesaurus. Code C50643.

Headache in erect position, after lumbar puncture; due to lowering of intracranial pressure by leakage of cerebrospinal fluid through the needle tract. 